\title{
Lung cancer screening strategy for non-high-risk individuals: a narrative review
}

\author{
Fangqiu Fu ${ }^{1,2,3 \#}$, Yaodong Zhou ${ }^{1,2,3 \#}$, Yang Zhang ${ }^{1,2,3}$, Haiquan Chen ${ }^{1,2,3}$ \\ ${ }^{1}$ Department of Thoracic Surgery and State Key Laboratory of Genetic Engineering, Fudan University Shanghai Cancer Center, Shanghai, China; \\ ${ }^{2}$ Institute of Thoracic Oncology, Fudan University, Shanghai, China; ${ }^{3}$ Department of Oncology, Shanghai Medical College, Fudan University, \\ Shanghai, China \\ Contributions: (I) Conception and design: All authors; (II) Administrative support: Y Zhang and H Chen; (III) Provision of study materials or patients: \\ All authors; (IV) Collection and assembly of data: All authors; (V) Data analysis and interpretation: All authors; (VI) Manuscript writing: All authors; \\ (VII) Final approval of manuscript: All authors. \\ "These authors contributed equally to this work. \\ Correspondence to: Haiquan Chen, MD; Yang Zhang, MD. Department of Thoracic Surgery, Fudan University Shanghai Cancer Center, 270 Dong- \\ An Road, Shanghai 200032, China. Email: hqchen1@yahoo.com; fduzhangyang1987@hotmail.com.
}

\begin{abstract}
Lung cancer is the deadliest malignancy worldwide, accounting for almost $20 \%$ of all cancer deaths. Clinical trials, such as NLST and NELSON, have proved the survival benefit of lung cancer screening using low-dose computed tomography (LDCT), and most of the lung cancer screening guidelines recommended annual lung cancer screening by LDCT for high-risk individuals. However, a relatively high proportion of lung cancer patients do not have risk factors, and it is questionable whether non-highrisk individuals should receive LDCT screening. In this review, we reviewed risk factors of lung cancer and summarized the benefits and potential harms of LDCT screening. After clarifying the differences between China and western countries in lung cancer screening, we recommended that non-high-risk individuals should receive LDCT screening with an interval of five to ten years. To better balance benefits and harms from LDCT screening, we also proposed a flexible screening strategy using LDCT based on lung cancer risk. Hopefully, it may help reduce unnecessary radiation exposure from CT scans while decreasing mortality of lung cancer.
\end{abstract}

Keywords: Lung cancer screening; low-dose computed tomography (LDCT); lung cancer risk; interval

Submitted Aug 13, 2020. Accepted for publication Oct 14, 2020.

doi: $10.21037 /$ tlcr-20-943

View this article at: http://dx.doi.org/10.21037/tlcr-20-943

\section{Introduction}

Lung cancer is the deadliest malignancy worldwide, with estimated over 1.7 million deaths in 2018 (1). Strenuous efforts have been made to improve the survival of lung cancer, and lung cancer screening is proved to be an effective method with relatively limited harm through early detection and treatment (2). Among all screening technologies, low-dose computed tomography (LDCT) stands out for its high sensitivity and non-invasiveness $(3,4)$. The association between LDCT lung cancer screening and survival benefit was observed in National Lung Screening
Trial (NLST) and Dutch-Belgian Lung Cancer Screening Trial (Nederlands-Leuvens Longkanker Screenings Onderzoek, NELSON) (5,6). However, NLST (5) enrolled asymptomatic participants aged 55-74 years and with a smoking history of at least 30 pack-year, and NELSON (7) enrolled individuals aged 50-75 years, who had smoked either $\geq 15$ cigarettes per day for 25 years or $\geq 10$ cigarettes per day for 30 years and were still smoking or had quit $<10$ years ago. These two trials only enrolled high-risk individuals who met the criteria of age and smoking histories, so most guidelines merely recommended LDCT lung cancer screening for high-risk individuals. 
Nevertheless, previous studies demonstrated that an estimated $40-60 \%$ of patients with lung cancer did not meet the US Preventative Task Force (USPTF) criteria, originated from the NLST eligibility criteria $(8,9)$. Besides, $10 \%$ to $25 \%$ of all lung cancers occurred in never smokers $(10,11)$. Therefore, non-high-risk individuals might also need lung cancer screening. This review aimed to give an overview on the risk factors of lung cancer, summarized benefits and harms of LDCT screening, and proposed a tailored screening programs using LDCT for non-high-risk individuals.

We present the following article in accordance with the Narrative Review reporting checklist (available at http:// dx.doi.org/10.21037/tlcr-20-943).

\section{Methods}

The literature research was conducted in the PubMed/ MEDLINE database on June $18^{\text {th }}, 2020$. The following search terms were used: lung cancer screening, low-dose CT screening, and lung nodule screening. Only English articles, published between January $1^{\text {st }}, 1990$ and June $18^{\text {th }}$, 2020, were enrolled in this review.

\section{Discussion}

\section{Risk factors for lung cancer}

In 2018, there were more than 2 million estimated new cases of lung cancer worldwide, accounting for $11.6 \%$ of all new cases with cancer (1). In the United States, 228 thousand individuals were estimated to develop lung cancer in 2020, accounting for $12.7 \%$ of all new cases with cancer (12). Especially in China, approximately $17.1 \%$ of new cancer cases had lung cancer (13). Therefore, to reduce the incidence of lung cancer, we need to identify risk factors.

\section{Smoking}

Cigarette smoking is considered to be a main risk factor. The association between the number of cigarettes and the risk of lung cancer was observed in previous studies $(14,15)$. The second-hand smoking also contributed to the carcinogenesis of lung cancer (16). Smoking cessation could reduce lung cancer risk $(16,17)$, and some guidelines also recommended smoking cessation while receiving lung cancer screening. Smoking addiction results from the presence of nicotine in tobacco. However, it is not nicotine but the exposure to tar (the total matter of smoke after removing nicotine and water) that leads to the carcinogenesis of lung cancer (18). Tar consists of 3,500 chemical substances and approximately 60 of them are known carcinogens (19).

\section{Age}

As time goes by, shortening of telomeres after many times of cell replication cycles and accumulative DNA damage may lead to the carcinogenesis of lung cancer. The young individuals have less possibility to develop lung cancer, compared with the old (20). However, the lung cancer incidence might be affected by the methods of lung cancer screening and the extent of ordinary persons understanding about lung cancer. Nowadays, with the development of the society, especially in some developing countries (such as China), LDCT is widely applied clinically, and the detection rate of lung cancer in young population increases $(21,22)$.

\section{Gender}

Traditionally, men are more likely to develop lung cancer than women. However, the trends of lung cancer incidence in men and women changed dramatically. Jemal et al. reviewed the nationwide population-based incidence of lung cancer in America and found that the age-specific incidence decreased generally among both men and women with the age of 30 to 54 years old (23). Nevertheless, the declines among men have been steeper (23). During 2010 and 2014, lung cancer incidence was higher in women than men (23). In terms of mechanism, the expression of estrogen receptor (ER) alpha and ER beta were found to be increased in lung cancer tissues (24), and ER ligands could activate MAPK pathway and promote cell growth (25).

\section{Environmental factors}

Environmental factors may also contribute to carcinogenesis of lung cancer. They consist of indoor air pollution, including coal (26-28), biomass (29), and cooking fumes (30), outdoor air pollution $(31,32)$, and occupational agents, including asbestos (33), arsenic (34), and silica $(35,36)$. If we reduce the exposure to these environmental factors, the incidence of lung cancer should be decreased.

\section{Genetic factors}

Individuals response to the same environmental exposure differently. For instance, although smoking is considered to be a main risk factor of lung cancer, the majority of smokers will not develop lung cancer in their lifetime (37) 
and some never-smokers might also develop lung cancer. Moreover, the percentage of never smokers in lung cancer patients is about $10 \%$ to $20 \%$ in western countries (38), but it is as high as $50 \%$ to $63 \%$ in east-Asian population (39-41). Mechanically, gene nutation might be a significant factor and some genetic variations might contribute to the carcinogenesis of non-small cell lung cancer regardless of smoking history. In 2005, Bell et al. (42) reported a family with multiple cases of non-small cell lung cancer associated with the germline EGFR-T790M mutation. Subsequent studies identified relevant mutations in HER2, TP53, and $B R C A 2$ as susceptible variations $(43,44)$. Not only germline mutation but also single nucleotide polymorphism may result in the predisposition to lung cancer. Genome-wide association studies have identified rs3769821, rs2293607, rs1200399, rs17038564, rs35201538, and rs4573350 as risk loci for lung cancer in Chinese population (45).

\section{Benefits of LDCT}

\section{Reducing lung cancer mortality}

Reduction in lung cancer mortality remains as the major benefit for LDCT. In NLST (53,454 participants), there were 247 lung cancer-specific deaths per 100,000 personyears in the LDCT group and 309 lung cancer-specific deaths per 100,000 person-years in the radiography group, leading to a relative reduction in lung cancer mortality using LDCT of $20.0 \%$ [95\% confidence interval (CI): 6.8-26.7\%; $\mathrm{P}=0.004]$ (5). As for all-cause mortality, it was reduced in the LDCT group by $6.7 \%$ (95\% CI: 1.2-13.6\%; $\mathrm{P}=0.02)$ (5). Another lung cancer screening trial, NELSON (13,195 participants), investigated the association between LDCT lung cancer screening and survival benefit in 13,195 males and 2,594 females. Among men, lung cancer mortality was 2.50 deaths per 1,000 person-years for the LDCT group and 3.30 deaths per 1,000 person-years for the control group (no screening methods). The final results showed the cumulative rate ratio for lung cancer-specific death was 0.76 (95\% CI: $0.61-0.94 ; \mathrm{P}=0.01)$ at 10 years in the LDCT group, compared with the control group (6). Among women, the rate ratio was 0.67 (95\% CI: 0.38-1.14) at 10 years (6). However, there are some conflicting results. The DLCST (46) (4,104 participants) reported a hazard ratio (HR) of 1.03 (95\% CI: $0.66-1.60)$ in lung cancer mortality, the DANTE (47) (2,450 participants) reported a HR of 0.99 (95\% CI: 0.69-1.43), and the MILD (48) (4,099 participants) reported a HR of 1.52 (95\% CI: 0.63-3.65). The reason for no statistical difference in these trials may be the limited number of patients in the above studies, resulting in insufficient statistical power to detect lung cancer mortality reduction. Therefore, the results of NLST and NELSON are more convincing, and LDCT can reduce lung cancer mortality in high-risk individuals.

\section{Other incidental findings besides lung cancer}

During chest LDCT screening, abnormalities other than lung cancer could be found in lung, heart, chest wall, or breast, which might need clinical interference. In NLST, incidental findings were detected in $7.5 \%$ of participants $(5,49)$, while they were detected in $6.7 \%$ of participants in NELSON (50). Although some unmeaningful findings may cause additional diagnostic processes and anxiety of patients, other clinically-relevant findings might lead to health benefits for participants. For instance, LDCT could be useful in the early detection of other smokingrelated diseases besides lung cancer, such as COPD and cardiovascular diseases (51-53). Future studies are required to quantify the benefits of incidental findings on LDCT.

\section{Harms of LDCT}

\section{Radiation exposure}

The individuals receiving LDCT are exposed to radiation. The effective dose of radiation of LDCT is estimated to be $1.5 \mathrm{mSv}$ per examination (54). One study based on the NLST data found that approximately one cancer death might be caused by radiation from imaging per 2,500 participants screened (54). According to the National Comprehensive Cancer Network (NCCN) lung cancer screening guidelines (55), annual screening LDCT is recommended for high-risk individuals. As a result, a single person needs to receive more than 20 times of LDCT in his or her lifetime. Therefore, to minimize the radiation risk from LDCT screening, the contradiction regarding expected benefits versus potential harms should be carefully balanced. Especially for the individuals with negative results at the baseline CT, the intervals of LDCT screening need to be carefully considered. In addition, less radiation dose per LDCT is expected due to revolutionized radiological technologies in the future.

\section{False-positive findings}

Some other lesions, such as inflammatory lesions, might showed a similar appearance as lung cancer. Most of the LDCT-detected lesions are not malignant, and the falsepositive finding is an inevitable issue. In NLST, of all the 
participants in the three rounds of LDCT, $24.2 \%$ were classified as positive, and $23.3 \%$ were found to be falsepositive, leading to the fact that $96.4 \%$ of the participants with positive results were false positive eventually (5). In NELSON, of those with positive results, $59.4 \%$ were considered to be false-positive, and the overall false-positive rate was $1.2 \%(7,56)$. The possible reason might be that the threshold for a positive screening test result in NELSON is higher than that in NLST (2). A proper CT scan strategy might help reduce the false-positive findings, and other methods to distinguish the malignant from the benign is also required in future studies.

\section{Overdiagnosis and overtreatment}

Overdiagnosis is defined as lung cancer detected by screening which would not otherwise affect the lifetime of patients if untreated, and overdiagnosis could lead to overtreatment. Overdiagnosis and overtreatment can result in unnecessary diagnostic procedures, the anxiety of patients, and increased medical expenses without any survival benefits. The excess analyses of NLST data suggested that the overdiagnosis rate in lung cancer patients was $18.5 \%$ (57), while the analyses based on microsimulation modeling demonstrated that was $9.6 \%$ (58). Therefore, the calculation of the overdiagnosis rate varies from the selected models. Besides, the analyses based on the data from clinical trials are flawed, because the enrolled participants must meet specific requirements and followed a relatively strict screening protocol. In real-world clinical practice, the scenarios could be much more complicated, so the results from clinical trials might be not as reliable as we thought. Moreover, the above analyses of overdiagnosis were based on the whole population. As for a single individual, it is not an easy task to identify whether he or she will be over-diagnosed, and he or she might be willing to reduce the possibility of lung cancer death by any means. Therefore, the overdiagnoses of LDCT might need a second thought in real-world clinical practice.

\section{The differences between China and western countries in lung cancer screening}

Most of lung cancer screening guidelines were released by western associations and societies (Table 1). NCCN recommended annual LDCT for either current smokers or former smokers quitting $<15$ years with a smoking history of $\geq 30$ pack-year, who was 55 to 77 years old, or individuals with a smoking history of $\geq 20$ pack-year and additional risk factors (other than second-hand smoke), who was no less than 50 years old (55). American Association for Thoracic Surgery suggested annual LDCT for individuals with a smoking history of $\geq 30$ pack-year, who was 55 to 79 years old, or individuals with a smoking history of $\geq 20$ pack-year and a cumulative risk of developing lung cancer of $5 \%$, who was no less than 50 years old (59). For either current smokers or former smokers quitting $<15$ years with a smoking history of $\geq 30$ pack-year, US Preventive Services Task Force recommended annual LDCT for individuals with the age between 55 and 80 (60), while American Cancer Society suggested it for those with the age between 55 and 74 (61). In addition, some risk prediction models have been developed (62-64). Based on data from the BetaCarotene and Retinol Efficacy Study (CARET), Bach et al. (62) developed a lung cancer risk prediction model incorporating smoking history, asbestos exposure, sex, and age to predict annual absolute lung cancer risk of eversmoking individuals aged over 45 years. Nevertheless, the current models were not representative for generalization and the selection of factors might be different in different models. Therefore, no prediction model is utilized clinically, and a good and unified prediction model is needed currently.

The health insurance and access for LDCT were distinct between China and western countries. In China, LDCT is not only very cheap (about 30 US dollars), but also can be covered by healthcare insurance. The situation was completely different in America, where private health insurance and Medicare programs offer screening programs only for some eligible people. Moreover, in China, LDCT can usually be performed within the same day of appointment in some hospitals, which is not practical in European countries or America. As a result, in China, LDCT is easily accessible for both high-risk and non-highrisk individuals. Many employers in China have added LDCT into their regular annual health examination. As a result, almost everyone in China was accessible to LDCT if he or she wanted. Therefore, in clinical practice, some individuals from China received excessive LDCT, most of which was unnecessary.

Due to the discrepancies in clinical practice, the results of screening are different between China and western countries. Traditionally, smoking and age are considered to be risk factors for lung cancer $(65,66)$. NLST and NELSON only enrolled high-risk individuals, who met the specific criteria on age and smoking history. The final results demonstrated that lung cancer screening using LDCT 
Table 1 The criteria for high-risk individuals in different guidelines

\begin{tabular}{|c|c|c|c|}
\hline Institution & Age & Smoking history & Interval of LDCT \\
\hline Group 1 & $55-77$ & $\begin{array}{c}\geq 30 \text { pack-year and either current smoker or former smoker } \\
\text { quitting }<15 \text { years }\end{array}$ & Every year \\
\hline Group 2 & $\geq 50$ & $\begin{array}{l}\geq 20 \text { pack-year and with additional risk factors (other than } \\
\text { second-hand smoke) }\end{array}$ & Every year \\
\hline \multicolumn{4}{|c|}{ American Association for Thoracic Surgery (59) } \\
\hline Group 1 & $55-79$ & $\geq 30$ pack-year & Every year \\
\hline Group 2 & $\geq 50$ & $\begin{array}{l}\geq 20 \text { pack-year with a cumulative risk of developing lung cancer } \\
\text { of } 5 \%\end{array}$ & Every year \\
\hline USPSTF (60) & $55-80$ & $\begin{array}{c}\geq 30 \text { pack-year and either current smoker or former smoker } \\
\text { quitting }<15 \text { years }\end{array}$ & Every year \\
\hline
\end{tabular}

was associated with improved survival. Hence lung cancer screening guidelines, suggested that lung cancer screening using LDCT was only recommended for high-risk individuals annually (Table 1). The integration of smoking cession and lung cancer screening is recommended in many western countries (67). However, it is not the case in China. Previously, we analyzed LDCT screening data from 11,332 participants in Shanghai and found that there was no statistically significant difference between the incidences of primary lung cancer in smokers and nonsmokers (68). Furthermore, we investigated 8,392 employees from 6 hospitals in different regions of China, who received LDCT as a part of regular health examination (21). The results demonstrated that the lung cancer detection rate was significantly greater in female than male $(2.5 \%$ vs. $1.3 \%$, $\mathrm{P}=0.001)$. There was also a greater detection rate among nonsmokers than smokers, although there was no significant difference $(2.2 \%$ vs. $1.4 \%, \mathrm{P}=0.092)$. The detection rate in young employees was greater than before. Moreover, $95.5 \%$ of LDCT-detected lung cancer radiologically presented as ground-glass opacity (21). Another study, which investigated the lung cancer morbidity and mortality rate in Xuanwei City, China, also reveal high incidence in females and an early age peak in lung cancer death (22). Above studies revealed that the "traditionally-believed lowrisk" population might also face a high risk of lung cancer. In spite of unknown reasons behind this phenomenon, this special group of individuals needs more attention and might benefit from lung cancer screening using LDCT.

\section{The necessity of LDCT screening for non-bigh-risk individuals}

In the United States, about $40-60 \%$ of lung cancer patients did not meet high-risk criteria of NLST $(8,9)$. These patients should not receive LDCT according to the current guidelines of lung cancer screening. There are few existing clinical trials to investigate the use of LDCT in low-risk individuals. Most of evidence came from NLST (69), which was not originally designed for this. Wei et al. (70) investigated the performance of lung cancer screening with LDCT in 1,411 high-risk and 558 non-high-risk individuals in China. The results demonstrated that the positive rate was $9.7 \%$ for all participants and $11.3 \%$ for the high-risk individuals. In our clinical scenarios, a relatively high proportion of lung cancer patients did not have risk factors. Hence non-highrisk individuals might also need lung cancer screening. Moreover, Detterbeck (71) proposed that lung cancer could be divided into types with rapid growth, usual growth, slow growth, very slow growth, no growth and spontaneous regression according to their growth rates. LDCT screening intervention will inevitably detect more slow-growing tumors or indolent tumors especially for non-high-risk individuals. In fact, the majority of LDCT-detected lung cancers in nonhigh-risk individuals progress very slowly and are still at stage 0/I disease (21). Even if the non-high-risk participants develop new suspected lung cancer during the long screening interval, the situations are likely to be manageable and the survival should not be affected. Therefore, a longer interval will be more appropriate for non-high-risk individuals if the 

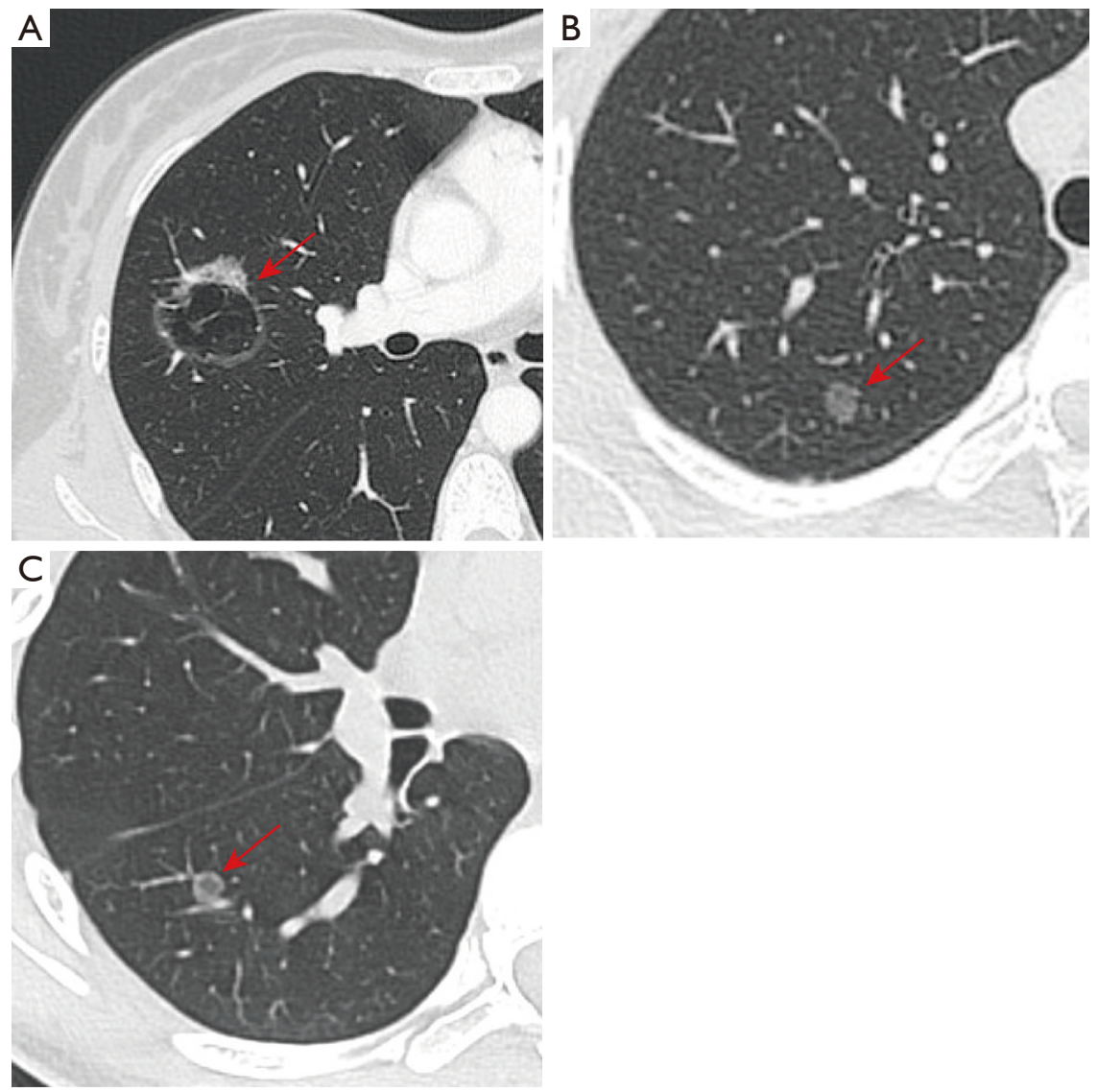

Figure 1 The computed tomography images for ground-glass opacity-featured lung adenocarcinoma. (A) The typical computed tomography image for a 38-year-old woman with lung cancer. (B,C) The typical computed tomography images for two 14-year-old teenagers with preinvasive lung cancer. Red arrows indicate lesions for patients with lung cancer.

baseline CT is negative.

If we prolong the interval of LDCT to reduce the potential harms from it, LDCT might be beneficial for the non-high-risk individuals. We counted a 38-yearold woman with one lung nodule (Figure 1A), who did not have a history of smoking. She received lobectomy and systematic mediastinal lymph node dissection, and the pathological diagnosis was lung adenocarcinoma (pT2aN1M0). If this patient had received LDCT earlier, she may have just needed sublobar resection without lymph node dissection, and the prognosis would have been better. Moreover, we also met two 14-year-old teenagers without smoking history, whose pathological results were preinvasive adenocarcinoma (Figure 1B,C). Although it is not common in clinical practice, it emphasizes the importance of LDCT screening for non-high-risk individuals, especially for young and non-smoking individuals.

\section{The interval of LDCT screening for non-bigh-risk individuals}

Currently, most guidelines on lung cancer screening recommend annual lung cancer screening using LDCT in high-risk individuals (Table 1). However, the choice of a yearly CT did not come from biological mechanisms, and it is debatable whether all eligible individuals should receive annual LDCT screening. Schreuder et al. (67) investigated the participants in NLST who underwent a baseline CT and a first annual negative follow-up scan and found out that the model, incorporating patient characteristics and baseline scan morphology, was significantly superior to the annual strategy. The Italian MILD trial remains as the only randomized controlled trial to compare different screening intervals using LDCT. In MILD (48), there were 4,099 high-risk participants, 1,723 randomized to the control group (no screening), 1,186 to the biennial LDCT group, 


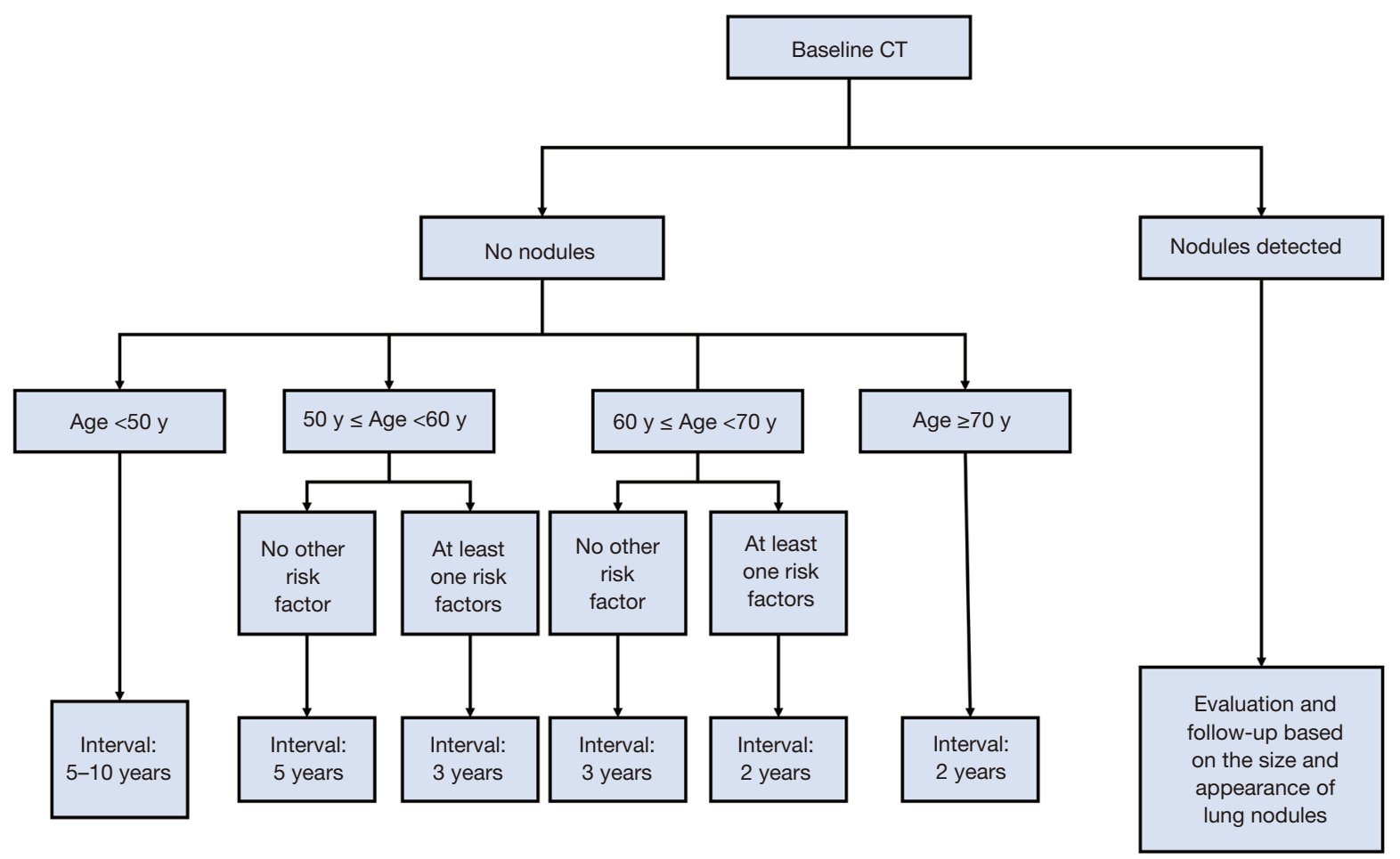

Figure 2 A screening strategy for lung cancer screening based on risk factors.

and 1,190 to the annual LDCT group. No difference was observed in lung cancer mortality between the biennial and annual group. Biennial screening could save about one third of LDCT scans with similar performance indicators as compared to annual screening (72). Therefore, we believe that two years is a better interval for high-risk individuals using LDCT screening, and future trials are urged to clarify this issue. As for non-high-risk individuals, an interval of more than two years has been suggested for low-risk individuals $(73,74)$. Therefore, we believe that the current strategy for lung cancer screening using LDCT might be too tight, and a loose strategy should be more appropriate.

Here, we proposed a new screening strategy with flexible intervals of LDCT based on lung cancer risks (Figure 2). For participants with an age of less than 50, the interval might be five to ten years, if the baseline CT is negative. For those between 50 and 60 years old, the interval might be three to five years according to the number of risk factors. For those between 60 and 70 years old, it might be two to three years. For those with an age of more than 70 years, it might be two years.

\section{Conclusions}

In summary, there are some differences in LDCT screening between China and western countries. LDCT should be recommended for not only high-risk but also non-high-risk individuals. To balance the benefits and harms, the nonhigh-risk individuals should receive LDCT every five or ten years. We also put forward a screening strategy based on lung cancer risk. Hopefully, it might help reduce radiation exposure from CT scans while decreasing the mortality of lung cancer.

\section{Acknowledgments}

Funding: This work was supported by the National Natural Science Foundation of China (81930073 and 81772466), Shanghai Municipal Science and Technology Major Project (Grant No. 2017SHZDZX01, VBH1323001/026), Shanghai Municipal Key Clinical Specialty Project (SHSLCZDZK02104), and Pilot Project of Fudan University (IDF159034).

\section{Footnote}

Reporting Checklist: The authors have completed the Narrative Review reporting checklist. Available at http:// dx.doi.org/10.21037/tlcr-20-943 
Peer Review File: Available at http://dx.doi.org/10.21037/tlcr20-943

Conflicts of Interest: All authors have completed the ICMJE uniform disclosure form (available at http://dx.doi. org/10.21037/tlcr-20-943). The authors have no conflicts of interest to declare.

Ethical Statement: The authors are accountable for all aspects of the work in ensuring that questions related to the accuracy or integrity of any part of the work are appropriately investigated and resolved.

Open Access Statement: This is an Open Access article distributed in accordance with the Creative Commons Attribution-NonCommercial-NoDerivs 4.0 International License (CC BY-NC-ND 4.0), which permits the noncommercial replication and distribution of the article with the strict proviso that no changes or edits are made and the original work is properly cited (including links to both the formal publication through the relevant DOI and the license). See: https://creativecommons.org/licenses/by-nc-nd/4.0/.

\section{References}

1. Bray F, Ferlay J, Soerjomataram I, et al. Global cancer statistics 2018: GLOBOCAN estimates of incidence and mortality worldwide for 36 cancers in 185 countries. CA Cancer J Clin 2018;68:394-424.

2. van der Aalst CM, Ten Haaf K, de Koning HJ. Lung cancer screening: latest developments and unanswered questions. Lancet Respir Med 2016;4:749-61.

3. Mortani Barbosa EJ Jr, Yang R, Hershman M. Real World Lung Cancer CT Screening Performance, Smoking Behavior, and Adherence to Recommendations: LungRADS Category and Smoking Status Predict Adherence. AJR Am J Roentgenol 2020. [Epub ahead of print]. doi: 10.2214/AJR.20.23637.

4. Li M, Hsu W, Xie X, et al. SACNN: Self-Attention Convolutional Neural Network for Low-Dose CT Denoising With Self-Supervised Perceptual Loss Network. IEEE Trans Med Imaging 2020;39:2289-301.

5. Aberle DR, Adams AM, Berg CD, et al. Reduced LungCancer Mortality with Low-Dose Computed Tomographic Screening. N Engl J Med 2011;365:395-409.

6. de Koning HJ, van der Aalst CM, de Jong PA, et al. Reduced Lung-Cancer Mortality with Volume CT Screening in a Randomized Trial. N Engl J Med
2020;382:503-13.

7. Horeweg N, van der Aalst CM, Vliegenthart R, et al. Volumetric computed tomography screening for lung cancer: three rounds of the NELSON trial. Eur Respir J 2013;42:1659-67.

8. Nemesure B, Plank A, Reagan L, et al. Evaluating efficacy of current lung cancer screening guidelines. J Med Screen 2017;24:208-13.

9. Aldrich MC, Mercaldo SF, Sandler KL, et al. Evaluation of USPSTF Lung Cancer Screening Guidelines Among African American Adult Smokers. JAMA Oncol 2019;5:1318-24.

10. Koo LC, Ho JH. Worldwide epidemiological patterns of lung cancer in nonsmokers. Int J Epidemiol 1990;19 Suppl 1:S14-23.

11. Parkin DM, Bray F, Ferlay J, et al. Global cancer statistics, 2002. CA Cancer J Clin 2005;55:74-108.

12. Siegel RL, Miller KD, Jemal A. Cancer statistics, 2020. CA Cancer J Clin 2020;70:7-30.

13. Chen W, Zheng R, Baade PD, et al. Cancer statistics in China, 2015. CA Cancer J Clin 2016;66:115-32.

14. Hoffman FL. Cancer and Smoking Habits. Ann Surg 1931;93:50-67.

15. Gandini S, Botteri E, Iodice S, et al. Tobacco smoking and cancer: a meta-analysis. Int J Cancer 2008;122:155-64.

16. Besaratinia A, Pfeifer GP. Second-hand smoke and human lung cancer. Lancet Oncol 2008;9:657-66.

17. Peto R, Darby S, Deo H, et al. Smoking, smoking cessation, and lung cancer in the UK since 1950: combination of national statistics with two case-control studies. BMJ 2000;321:323-9.

18. Akhtar N, Bansal JG. Risk factors of Lung Cancer in nonsmoker. Curr Probl Cancer 2017;41:328-39.

19. de Groot P, Munden RF. Lung cancer epidemiology, risk factors, and prevention. Radiol Clin North Am 2012;50:863-76.

20. Thun MJ, Henley SJ, Burns D, et al. Lung cancer death rates in lifelong nonsmokers. J Natl Cancer Inst 2006;98:691-9.

21. Zhang Y, Jheon S, Li H, et al. Results of low-dose computed tomography as a regular health examination among Chinese hospital employees. J Thorac Cardiovasc Surg 2020;160:824-31.e4.

22. Xiao $Y$, Shao $Y, Y u X$, et al. The epidemic status and risk factors of lung cancer in Xuanwei City, Yunnan Province, China. Front Med 2012;6:388-94.

23. Jemal A, Miller KD, Ma J, et al. Higher Lung Cancer Incidence in Young Women Than Young Men in the 
United States. N Engl J Med 2018;378:1999-2009.

24. Kerr A 2nd, Eliason JF, Wittliff JL. Steroid receptor and growth factor receptor expression in human nonsmall cell lung cancers using cells procured by laser-capture microdissection. Adv Exp Med Biol 2008;617:377-84.

25. Hershberger PA, Stabile LP, Kanterewicz B, et al. Estrogen receptor beta (ER $\beta)$ subtype-specific ligands increase transcription, p44/p42 mitogen activated protein kinase (MAPK) activation and growth in human nonsmall cell lung cancer cells. J Steroid Biochem Mol Biol 2009;116:102-9.

26. Bessö A, Nyberg F, Pershagen G. Air pollution and lung cancer mortality in the vicinity of a nonferrous metal smelter in Sweden. Int J Cancer 2003;107:448-52.

27. Zeka A, Mannetje A, Zaridze D, et al. Lung cancer and occupation in nonsmokers: a multicenter case-control study in Europe. Epidemiology 2006;17:615-23.

28. Lan Q, He X, Shen M, et al. Variation in lung cancer risk by smoky coal subtype in Xuanwei, China. Int J Cancer 2008;123:2164-9.

29. Lissowska J, Bardin-Mikolajczak A, Fletcher T, et al. Lung cancer and indoor pollution from heating and cooking with solid fuels: the IARC international multicentre casecontrol study in Eastern/Central Europe and the United Kingdom. Am J Epidemiol 2005;162:326-33.

30. Seow A, Poh WT, Teh M, et al. Fumes from meat cooking and lung cancer risk in Chinese women. Cancer Epidemiol Biomarkers Prev 2000;9:1215-21.

31. Liu C, Chen R, Sera F, et al. Ambient Particulate Air Pollution and Daily Mortality in 652 Cities. N Engl J Med 2019;381:705-15.

32. Vineis P, Hoek G, Krzyzanowski M, et al. Air pollution and risk of lung cancer in a prospective study in Europe. Int J Cancer 2006;119:169-74.

33. Shields TW. General thoracic surgery. Lippincott: Williams \& Wilkins, 2005.

34. Pershagen G, Wall S, Taube A, et al. On the interaction between occupational arsenic exposure and smoking and its relationship to lung cancer. Scand J Work Environ Health 1981;7:302-9.

35. Hessel PA, Sluis-Cremer GK. Silica, silicosis, and lung cancer among ceramic workers: a case-referent study. Am J Ind Med 1987;12:219-22.

36. Siemiatycki J, Gérin M, Dewar R, et al. Silica and cancer associations from a multicancer occupational exposure case-referent study. IARC Sci Publ 1990:29-42.

37. Spitz MR, Wei Q, Dong Q, et al. Genetic susceptibility to lung cancer: the role of DNA damage and repair. Cancer
Epidemiol Biomarkers Prev 2003;12:689-98.

38. Sun S, Schiller JH, Gazdar AF. Lung cancer in never smokers--a different disease. Nat Rev Cancer 2007;7:778-90.

39. Fu F, Zhang Y, Wen Z, et al. Distinct Prognostic Factors in Patients with Stage I Non-Small Cell Lung Cancer with Radiologic Part-Solid or Solid Lesions. J Thorac Oncol 2019;14:2133-42.

40. Li S, Li L, Zhu Y, et al. Coexistence of EGFR with KRAS, or BRAF, or PIK3CA somatic mutations in lung cancer: a comprehensive mutation profiling from 5125 Chinese cohorts. Br J Cancer 2014;110:2812-20.

41. Kim H, Goo JM, Kim Y'T, et al. Validation of the eighth edition clinical $\mathrm{T}$ categorization system for clinical stage IA resected lung adenocarcinomas: Prognostic implications of the ground-glass opacity component. J Thorac Oncol 2019;15:580-8.

42. Bell DW, Gore I, Okimoto RA, et al. Inherited susceptibility to lung cancer may be associated with the T790M drug resistance mutation in EGFR. Nat Genet 2005;37:1315-6.

43. Yamamoto H, Higasa K, Sakaguchi M, et al. Novel germline mutation in the transmembrane domain of HER2 in familial lung adenocarcinomas. J Natl Cancer Inst 2014;106:djt338.

44. Parry EM, Gable DL, Stanley SE, et al. Germline Mutations in DNA Repair Genes in Lung Adenocarcinoma. J Thorac Oncol 2017;12:1673-8.

45. Dai J, Zhu M, Wang Y, et al. Identification of risk loci and a polygenic risk score for lung cancer: a large-scale prospective cohort study in Chinese populations. Lancet Respir Med 2019;7:881-91.

46. Wille MM, Dirksen A, Ashraf H, et al. Results of the Randomized Danish Lung Cancer Screening Trial with Focus on High-Risk Profiling. Am J Respir Crit Care Med 2016;193:542-51.

47. Infante M, Cavuto S, Lutman FR, et al. Long-Term Followup Results of the DANTE Trial, a Randomized Study of Lung Cancer Screening with Spiral Computed Tomography. Am J Respir Crit Care Med 2015;191:1166-75.

48. Pastorino U, Rossi M, Rosato V, et al. Annual or biennial CT screening versus observation in heavy smokers: 5-year results of the MILD trial. Eur J Cancer Prev 2012;21:308-15.

49. National Lung Screening Trial Research Team; Aberle DR, Berg CD, et al. The National Lung Screening Trial: overview and study design. Radiology 2011;258:243-53.

50. van de Wiel JC, Wang Y, Xu DM, et al. Neglectable benefit of searching for incidental findings in the DutchBelgian lung cancer screening trial (NELSON) using low- 
dose multidetector CT. Eur Radiol 2007;17:1474-82.

51. Watts JR Jr, Sonavane SK, Snell-Bergeon J, et al. Visual scoring of coronary artery calcification in lung cancer screening computed tomography: association with allcause and cardiovascular mortality risk. Coron Artery Dis 2015;26:157-62.

52. Mets OM, Vliegenthart R, Gondrie MJ, et al. Lung cancer screening CT-based prediction of cardiovascular events. JACC Cardiovasc Imaging 2013;6:899-907.

53. Mets OM, Buckens CF, Zanen P, et al. Identification of chronic obstructive pulmonary disease in lung cancer screening computed tomographic scans. JAMA 2011;306:1775-81.

54. Bach PB, Mirkin JN, Oliver TK, et al. Benefits and harms of CT screening for lung cancer: a systematic review. JAMA 2012;307:2418-29.

55. National comprehension cancer $n$. National Comprehensive Cancer Network (NCCN) clinical practice guidelines for lung cancer screening. 2020. Available online: https://www.nccn.org/professionals/physician_gls/ pdf/lung_screening.pdf. Accessed July 272020.

56. Yousaf-Khan U, van der Aalst C, de Jong PA, et al. Final screening round of the NELSON lung cancer screening trial: the effect of a 2.5 -year screening interval. Thorax 2017;72:48-56.

57. Patz EF Jr, Pinsky P, Gatsonis C, et al. Overdiagnosis in low-dose computed tomography screening for lung cancer. JAMA Intern Med 2014;174:269-74.

58. Ten Haaf K, de Koning HJ. Overdiagnosis in lung cancer screening: why modelling is essential. J Epidemiol Community Health 2015;69:1035-9.

59. Jaklitsch MT, Jacobson FL, Austin JH, et al. The American Association for Thoracic Surgery guidelines for lung cancer screening using low-dose computed tomography scans for lung cancer survivors and other high-risk groups. J Thorac Cardiovasc Surg 2012;144:33-8.

60. Blackmon SH, Feinglass SR. The United States Preventive Services Task Force recommendations for lung cancer screening. Thorac Surg Clin 2015;25:199-203.

61. Wender R, Fontham ET, Barrera E Jr, et al. American Cancer Society lung cancer screening guidelines. CA Cancer J Clin 2013;63:107-17.

Cite this article as: Fu F, Zhou Y, Zhang Y, Chen H. Lung cancer screening strategy for non-high-risk individuals: a narrative review. Transl Lung Cancer Res 2021;10(1):452-461. doi: 10.21037/tlcr-20-943
62. Bach PB, Elkin EB, Pastorino U, et al. Benchmarking lung cancer mortality rates in current and former smokers. Chest 2004;126:1742-9.

63. Spitz MR, Hong WK, Amos CI, et al. A risk model for prediction of lung cancer. J Natl Cancer Inst 2007;99:715-26.

64. Cassidy A, Myles JP, van Tongeren M, et al. The LLP risk model: an individual risk prediction model for lung cancer. Br J Cancer 2008;98:270-6.

65. Islami F, Torre LA, Jemal A. Global trends of lung cancer mortality and smoking prevalence. Transl Lung Cancer Res 2015;4:327-38.

66. Cassidy A, Duffy SW, Myles JP, et al. Lung cancer risk prediction: a tool for early detection. Int J Cancer 2007;120:1-6.

67. Schreuder A, Schaefer-Prokop CM, Scholten ET, et al. Lung cancer risk to personalise annual and biennial follow-up computed tomography screening. Thorax 2018. [Epub ahead of print]. doi: 10.1136/ thoraxjnl-2017-211107.

68. Luo X, Zheng S, Liu Q, et al. Should nonsmokers be excluded from early lung cancer screening with low-dose spiral computed tomography? Community-based practice in Shanghai. Transl Oncol 2017;10:485-90.

69. Kovalchik SA, Tammemagi M, Berg CD, et al. Targeting of low-dose CT screening according to the risk of lungcancer death. N Engl J Med 2013;369:245-54.

70. Wei MN, Su Z, Wang JN, et al. Performance of lung cancer screening with low-dose CT in Gejiu, Yunnan: A population-based, screening cohort study. Thorac Cancer 2020;11:1224-32.

71. Detterbeck FC. Cancer, concepts, cohorts and complexity: avoiding oversimplification of overdiagnosis. Thorax 2012;67:842-5.

72. Sverzellati N, Silva M, Calareso G, et al. Low-dose computed tomography for lung cancer screening: comparison of performance between annual and biennial screen. Eur Radiol 2016;26:3821-9.

73. Field JK, Duffy SW. Lung cancer CT screening: is annual screening necessary? Lancet Oncol 2016;17:543-4.

74. Field JK, Duffy SW. Lung cancer CT screening: are we ready to consider screening biennially in a subgroup of low-risk individuals? Thorax 2018;73:1006-7. 